\title{
Ausschreibung \\ für den Wettbewerb um die Carl-Diem-Plakette 1973/74
}

1. Der Deutsche Sportbund verleiht alle zwei Jahre für eine hervorragende sportwissenschaftliche Arbeit aus dem Zeitraum seit Beendigung des letzten Wettbewerbs die Carl-Diem-Plakette.

2. Mit der Verleihung der Carl-Diem-Plakette wird ein Geldpreis bis zur Höhe von DM 10000, - verbunden. Weitere eingereichte sportwissenschaftliche Arbeiten können im Rahmen des Wettbewerbs unter Zuerkennung eines Geldpreises ausgezeichnet werden oder lobende Erwähnung finden.

3. Einsendeschluß für die in sechsfacher Ausfertigung als Einschreibsendung an den Deutschen Sportbund, 6000 Frankfurt am Main 71, Otto-Fleck-Schneise 12, zu richtenden Arbeiten ist der 1. April 1974 (Poststempel). Später eingereichte Arbeiten können nicht berüdksichtigt werden.

4. Von den mit der Carl-Diem-Plakette oder mit anderen Preisen ausgezeichneten Arbeiten gehen die eingereichten sechs Belegstïcke in das Eigentum des Deutschen Sportbundes über. Von allen anderen Arbeiten verbleiben zwei Belegstücke als Archivexemplare beim Deutschen Sportbund.

5. Eine mit der Plakette oder mit einem Geldpreis ausgezeichnete Arbeit kann nach Entscheidung des Kuratoriums im Rahmen der "Wissenschaftlichen Schriftenreihe des Deutschen Sportbundes" veröffentlicht werden.

6. Der eingereichten Arbeit sind folgende Angaben beizufügen:

a) Name, Anschrift und kurz gefaßter Lebenslauf des Verfassers;

b) eine eidesstattliche Erklärung, daß die Arbeit selbständig vom Verfasser angefertigt worden ist und daß dieBewerbung den Bedingungen der Ausschreibung gerecht wird;

c) eine vollständige Zusammenstellung der benutzten Hilfsmittel und die Versicherung, daß keine anderen Hilfsmittel benutzt worden sind (soweit diese Angaben nicht bereits in der Arbeit selbst enthalten sind);

d) eine Erklärung, ob, wo und in welcher Fassung die Arbeit bereits Gegenstand eines Wettbewerbs war.

7. Das Ergebnis des Wettbewerbs wird in einer Veranstaltung des Deutschen Sportbundes bekanntgegeben.

Frankfurt am Main, 1. März 1973

Kuratorium für die Verleihung der Carl-Diem-Plakette gez. Prof. Dr.Dr.h.c. Dr.h.c. Erich Burck

(Vorsitzender) 